doi: $10.1897 / 05-149 R .1$

\title{
On The Limits Of Toxicant-Induced Tolerance Testing: Cotolerance And Response Variation Of Antibiotic Effects
}

Heike Schmitt, ${ }^{1,2,{ }^{*}}$ Bennie Martinali, ${ }^{1}$ Patrick Van Beelen, ${ }^{2}$ and Willem Seinen ${ }^{1}$

1. Institute for Risk Assessment Sciences, Utrecht University, P.O. Box 80176, 3508 TD Utrecht, The Netherlands

2. National Institute for Public Health and the Environment, P.O. Box 1, 3720 BA Bilthoven, The Netherlands

\begin{abstract}
Pollution-induced community tolerance (PICT) as an ecotoxicological test system has been claimed to detect pollutant effects highly specifically and sensitively. However, the specificity might be limited by the occurrence of cotolerance. Another limitation of the application of any ecotoxicological test system lies in variation of the measured responses. We tested the variation and the occurrence of cotolerance experimentally, using antibiotics as toxicants, soil microcosms as microbial communities, and tolerance determination in Biolog plates as PICT detection test. Bacteria have been discussed as being prone to multiple tolerances due to the possible accumulation of multiple resistance genes on mobile genetic elements. However, in our experiments, cotolerance occurred only between antibiotics of the same group (oxytetracycline and tetracycline), as expected from their identical mode of action. Cotolerance between oxytetracycline and tylosin in soil microcosms exposed to oxytetracycline was low, as was cotolerance to oxytetracycline in tylosin-exposed microcosms. We conclude that tolerance development to antibiotics in soils reflects the actual selection pressure rather than a general pattern of multiple resistances. Concerning variation, the PICT effect of tetracycline was well reproducible in two consecutive years. The response variation linked to PICT experiments in controlled microcosms was comparable to that of ecotoxicological test systems of equivalent complexity. In conclusion, our results support an application of the PICT methodology as an effective means to study the soil ecotoxicology of antibiotics.
\end{abstract}

\section{INTRODUCTION}

Environmental quality standards are most often based on single-species tests for the characterization of the effects of pollutants. These tests are mostly used as surrogates for higher levels of biological organization such as communities or ecosystems, which are more difficult to investigate. Still, some test approaches that are based on higher organization levels exist and bear significant advantages. One such approach is the so-called pollution-induced community tolerance (PICT), which has been applied in ecotoxicology for over 15 years [1] and has been reviewed recently $[2,3]$. Pollution-induced community tolerance is based on the assumption that communities would react to a toxicant stress by replacement of sensitive species or physiological adaptations that would render the community more tolerant. This community tolerance, in turn, can be tested with common laboratory ecotoxicology tests and used to characterize an environment as to whether toxicant stresses are present.

One of the main advantages of PICT is its specificity or causality. Pollutioninduced community tolerance might establish a toxicant-effect relationship more specifically than other measures of effect because the influence of confounding 
factors is reduced in tolerance testing [3]. This idea, however, is strongly dependent on the assumption that the tolerance to one agent would not be coupled to tolerance to another substance, a phenomenon discussed under the name of cotolerance [2] and observed frequently for metals [4-6]. The special attention for cotolerance dates back to the very early days of PICT, when Blanck et al. [1] pointed out that cotolerance would undermine the PICT approach if it was a frequent phenomenon. Theoretically, cotolerance can be expected for compounds that share a common mode of action and, more important, a common tolerance mechanism [2].

The phenomenon of cotolerance has frequently been described in an area of science not directly linked to ecotoxicology: multiple antibiotic resistance. This "cotolerance" of bacterial pathogens to several antibiotic compounds has increasingly been found in hospital environments. Bacteria can "accumulate" different resistance genes, especially as these are often located on mobile genetic elements such as transposons, integrons, or plasmids [7]. In addition, certain resistance mechanisms cause resistance to multiple substances at once [8].

Previous investigations in our lab showed that antibiotics could have toxic effects when they reach agricultural soils with manure from antibiotic-treated farm animals. We observed an increase in the community tolerance to sulfonamide, tetracycline, and macrolide antibiotics in soil microcosms amended with these antibacterial agents [9] (H. Schmitt, IRAS, Utrecht, The Netherlands, unpublished data). If cotolerance in bacteria were frequent, exposure to one antibiotic as environmental stressor would lead to cotolerance to other antibacterial substances. Alternatively, if the intrinsic cotolerance of soil bacteria to different antibacterial compound groups were limited, exposure to one antibiotic would lead to a tolerance development to only one antibiotic class at a time. In this investigation, we experimentally test this hypothesis by studying cotolerance in between the tetracycline group and between tetracyclines and macrolides.

The human health risks associated with antibiotic-resistant bacteria in the environment are largely unknown ([10];

www.asm.org/Academy/index.asp?bid=2114). Still, if cotolerance would also occur in soil microbial communities and if it was linked with genetically encoded resistance, this could add to the concerns about an environmental pool of resistance genes.

Variation in the observed response is an important issue when studying soil ecotoxicology, especially for test systems that might be used in regulatory toxicology. Pollution-induced community tolerance detects the community tolerance with short-term ecotoxicological tests, which have a potentially low variation due to their high degree of standardization. One such test is based on the respiration of organic substrates contained in multiwell plates (Biolog plates) [11-14]. However, little data have been presented regarding the response variation of PICT studies of microbial communities with Biolog plates.

The aim of this publication is to address two possible drawbacks associated with toxicant-induced tolerance testing. First, we investigated the strength of antibiotic cotolerance for mechanistically unrelated as well as related compounds as a possible bias in toxicant-induced tolerance. This included investigating the PICT effect of tetracycline. Second, we looked at the variation of PICT testing with Biolog plates.

\section{MATERIALS AND METHODS}


Environmental Toxicology and Chemistry: No. 25, pp. 1961-1968.

\section{Soil exposure}

Soil was sampled from a controlled field plot in 2003 and 2004 [15], and manure was obtained from Utrecht University farms (Utrecht, The Netherlands) from individual sows that had no record of antibiotic treatment in the past two months. Solid manure and urine were mixed to obtain pig slurries. Microcosms were set up as described previously [16]. In 2003, $6.6 \mathrm{ml}$ of slurry were added to $300 \mathrm{~g}$ soil (dry wt), resulting in an addition of $0.45 \mathrm{~g}$ of slurry dry matter per soil $\mathrm{kg}$. In 2004, $5 \mathrm{ml}$ slurry with a dry weight content of $71 \mathrm{~g} / \mathrm{kg}$ were added to 300 $\mathrm{g}$ soil (dry wt), equivalent to $1.1 \mathrm{~g}$ slurry dry matter per $1 \mathrm{~kg}$ soil.

The nitrogen content of the slurry was $5.96 \mathrm{~g} / \mathrm{kg}$ in 2004 , and the nitrogen input to the soil samples in 2004 equaled $91 \mathrm{mg} / \mathrm{kg}$ dry weight. This is equivalent to $186 \mathrm{~kg} \mathrm{~N} / \mathrm{ha}$ at a mixing depth of $20 \mathrm{~cm}$ and is thus in accordance with normal agricultural practice. Simultaneously with the slurry amendment, soils were spiked with a wide range of tetracycline concentrations: $0,0.1,1,10,100$, and $1,000 \mathrm{mg} / \mathrm{kg}$ dry weight. Tetracycline hydrochloride (Fluka, Zwijndrecht, The Netherlands; purity $>97 \%$ ) was applied as a solid substance or as watery solution. After $6 \mathrm{~d}$ (2003) or $7 \mathrm{~d}$ (2004), microbial inocula were extracted from the soil by shaking $20 \mathrm{~g}$ of soil for $1 \mathrm{~min}$ in a blender with $200 \mathrm{ml} 100-\mathrm{mM}$ phosphate buffer at $\mathrm{pH} 7$. The inocula were immediately frozen in 2-ml portions in liquid nitrogen and stored at $-80^{\circ} \mathrm{C}$ until further measurements.

\section{Community-level physiological fingerprints}

Community-level physiological fingerprints (CLPP) were determined with an inoculum-dilution-based method [17]. In short, 96-well microtiter plates, "ECO" microplates (Biolog, Hayward, CA, USA), prefilled with 31 organic substrates, were used for the determination of the bacterial metabolic activity. Substrate utilization over time is detected by redox changes that lead to coloring of a tetrazolium dye in the wells. The fingerprints were determined as the contribution of each organic substrate to the total coloring. Serially diluted inoculi were used in order to correct for inoculum density differences between the samples.

The plates were inoculated with $100 \mu \mathrm{l}$ per well of serial threefold dilutions of the thawed microbial extracts in 10-mM phosphate buffer ( $\mathrm{pH} \mathrm{7}$, containing $9 \mathrm{~g} / \mathrm{L}$ sodium chloride).

Each serial dilution was tested on 31 substrates and a water control well by inoculating one Biolog plate with three serial dilutions. The absorbance at $590 \mathrm{~nm}$ was determined once or twice daily until day $6(144 \mathrm{~h})$. This procedure yielded one color development curve for each substrate and for 12 inoculum densities. Per inoculum dilution, the color development curves for each of the substrates (well color development [WCD]) as well as the averaged absorption over all substrates (average WCD [AWCD]) were integrated over time to give the area under the curve (AUC; dimension: Absorbance $_{590 \mathrm{~nm}} \cdot \mathrm{h}$ ). The inoculum dilution at which coloring reached $50 \%$ of the maximum coloring (log WCD50) was calculated from a curve fit of the AUC against the inoculum dilution with a loglogistic function (GraphPad Prism Ver 3.00; GraphPad Software, San Diego, CA, USA). This was done for both the single substrates and the average coloring (AWCD). Community-level physiological profiling, the fingerprint of the metabolic activities in each soil, was calculated as the relative contribution of a substance to the average coloring, by dividing the AWCD 50 by the corresponding value for this substance, the WCD50: Fingerprint $=\log ($ AWCD50/WCD50) 
If substrates had their WCD50 at dilutions more than a factor 100 different from the AWCD50, their log WCD50 were set to 2 or -2 , respectively. The relative contributions of all 31 substrates were then analyzed using principal component analysis (without further scaling) and redundancy analysis with Monte Carlo permutations.

\section{Pollution-induced community tolerance}

Biolog plates were also used for the determination of the tolerance of the soil sample extracts to tetracycline [14]. The plates were amended with tetracycline (TC) to yield nominal concentrations of $0,0.1,0.3,1,3,10,30,100,300$, and $1,000 \mathrm{mg} / \mathrm{L}$. From the CLPP experiments, one inoculum dilution was chosen that led to sufficient coloring (average absorption on day 7 equaling $\sim 1.2$ in the control soil). Each plate was inoculated with $100 \mu \mathrm{l}$ per well of one tetracycline/inoculum combination, leading to triplicate measurements of each combination of soil extract and TC amendment for each of the 31 Biolog substrates. One to three times daily for $11 \mathrm{~d}(260 \mathrm{~h})$, coloring was determined. Per Biolog plate and substrate, the color formation was integrated over time, yielding AUCs of well color development. Response data for each soil sample thus consisted of AUCs for 31 substrates in triplicate, measured at 10 different Biolog plate TC concentrations. In order to integrate the coloring of the 31 substrates into one effect parameter, a normalized average of the coloring over all substrates was calculated. As substrates with different absolute coloring have a different weight on simple averaging (AWCD), and as some substrates are not influenced by antibiotic addition to Biolog plates, only the responding substrates were used for calculating the average. To this end, the responding substrates were defined as those with a robust dose-effect relationship between tetracycline plate amendment and reduction in coloring. The dose-effect relationship was judged from a log-logistic curve fit of their AUC against the plate concentration using GraphPad Prism [18]:

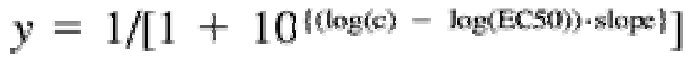

$$
\begin{aligned}
& \text { slope }=\log (9) /[\log (\mathrm{EC} 50)-\log (\mathrm{EC} 10)]
\end{aligned}
$$

A substrate was deemed responding if the curve fits of the $50 \%$ effective concentration ( $\log$ EC50) had $r^{2}$ values $>0.4$ and its log EC50 values had a standard deviation of EC50 $<1$. Each responding substrate was normalized by dividing the AUC in the Biolog plates exposed to tetracycline by the maximum $A \cup C$ for this substrate (AUC in the control plate without tetracycline addition). Per plate (thus, per tetracycline concentration), all AUCs of all responding substrates were averaged to yield average AUCs of rWCDs (average responding well color development ArWCD), ranging from 0 to 1 . These were fitted against the plate concentrations using a log-logistic dose-response curve as shown previously.

The correlation between tetracycline soil exposure and tolerance increase was tested by curve-fitting to a sigmoidal dose- response curve of the tolerance (as logEC50 of the averaged, responding substrates) versus the logarithm of the soil concentration.

\section{Cotolerance}

The cotolerance of one soil exposure to another antibiotic was determined in a similar way as for the single substrates, only that the antibiotic that cotolerance was studied for was now added to the Biolog plates in the same concentration range. The chemicals used were oxytetracycline dihydrate (Sigma Aldrich, 
Zwijndrecht, The Netherlands; purity $>99 \%$ ) and tylosin tartrate (Sigma Aldrich; purity $>90 \%)$.

Adaptation of microbial communities to oxytetracycline and tylosin was described elsewhere in detail (H. Schmitt, IRAS, Utrecht, The Netherlands, unpublished data). Briefly, soil microcosms of the same kind as described previously had been spiked with manure ( $2.9 \mathrm{~g}$ dry matter $/ \mathrm{kg}$ dry wt soil) and a range of oxytetracycline and tylosin concentrations. Tolerance development to oxytetracycline in oxytetracycline-exposed soils and tylosin in tylosin-exposed soils had been tested as described previously. For the present study, the microbial extracts stemming from these previous experiments have been tested for cotolerance to oxytetracycline, tylosin, and tetracycline.

\section{Selective plating}

Fresh extracts of the tetracycline-treated soils were plated in threefold serial dilutions on agar plates with one-tenth strength tryptone soya broth (TSB; Oxoid, Haarlem, The Netherlands). The plates were also amended with tetracycline in concentrations of $0,1,10$, and $100 \mathrm{mg} / \mathrm{L}$. Plate counts were evaluated after $8 \mathrm{~d}$ in order to include slow-growing cultivable bacteria. Statistical significance was evaluated by comparing the log-transformed colony counts between treatments and controls and correcting for multiple comparisons with the Bonferroni correction. In addition, curve-fitting of the logarithm of the number of colonyforming units (CFUs) versus the soil antibiotic concentration with a sigmoidal dose-response curve was performed according to $y=B+(T-B) /[1+$ $\left.10^{\{(\log (\mathrm{EC} 50)-\log (\mathrm{C})) \cdot \operatorname{slope}\}}\right]$ where $y=\log \mathrm{CFU}, \mathrm{B}$ and $\mathrm{T}=$ bottom and top of the doseresponse curve, $\mathrm{c}=$ antibiotic concentration in the soil, and slope $=$ hill-slope of the dose-response curve. It was assumed that the top of the dose-response curve was not yet reached (by artificially setting the top to 8 ).

\section{Sorption experiment}

The sorption coefficients of tetracycline for the soil used in this study were determined in a procedure based on Guideline 106 of the Organization for Economic Cooperation and Development (OECD) [19]. Diverging from the OECD guideline, the soil amount was chosen in a way that the total amount sorbed was in the same order of magnitude as the amount that remained in solution. Further, sodium azide $(10 \mathrm{mM})$ was used instead of calcium chloride, which is known to form complexes with tetracyclines. Aliquots of dried and sieved soil (1-mm mesh size) were shaken for $2 \mathrm{~d}$ with sodium azide and spiked with a range of tetracycline concentrations. After $2 \mathrm{~d}$ of shaking at room temperature, the supernatants of the centrifuged samples were analyzed by high-performance liquid chromatography (HPLC) on a reversed-phase column $(5 \mathrm{~cm} \times 4 \mathrm{~mm}, 3 \mu \mathrm{m}$, ODS-AQ $\mathrm{C}_{18}$; YMC, Kyoto, Japan). As mobile phase, $0.1 \%$ formic acid in water (A) and $0.1 \%$ formic acid in acetonitrile $(B)$ were used at a flow rate of $0.7 \mu \mathrm{l} / \mathrm{min}$ (A:B 85: 15), and tetracycline was detected by absorption at $360 \mathrm{~nm}$. Assuming that the mass balance is closed and no substance loss occurs, the sorption coefficients were determined as the ratio of the concentration in soil and water. An average was calculated over a range of antibiotic concentrations.

\section{Analysis}

Exemplarily for the three substances investigated, the concentrations of tetracycline in soil, in the PICT tolerance test and in the cotolerance experiment, were determined by HPLC. For the PICT experiment analysis, the remains of the bacterial inocula amended with the antibiotic after inoculating the Biolog plates 
were filtered ( $0.45 \mathrm{um})$ and subjected to HPLC with the same conditions as described previously. The concentrations of tetracycline well $(81-97 \%)$ matched the nominal concentrations at nominal concentrations of $0.3 \mathrm{mg} / \mathrm{L}$ and higher. The bacterial extracts of the soils exposed to $1000 \mathrm{mg} / \mathrm{kg}$ tetracycline contained about $1 \mathrm{mg} / \mathrm{L}$ tetracycline stemming from soil exposure. Because of the good agreement of the nominal and actual concentrations, nominal concentrations were applied when calculating dose-response curves.

Soil concentrations of tetracycline were verified after extraction. As extraction buffer, a freshly prepared mixture of methanol, $0.1 \mathrm{M}$ ethylene diamine tetraacetic acid, and McIlvaine buffer $(17.6 \mathrm{mM}$ citric acid and $16.5 \mathrm{mM}$ $\mathrm{Na} 2 \mathrm{HPO} 4)$ (2:1:1) [20] was used (all chemicals: Merck Nederland BV, Amsterdam, The Netherlands; analytical reagent grade). Four grams of soil were extracted three times with $5 \mathrm{ml}$ of extraction buffer by $5 \mathrm{~s}$ of vortexing, treatment in an ultrasonic bath for $5 \mathrm{~min}$, and centrifugation at 3,500 rpm for $10 \mathrm{~min}$. The extracts were used directly for HPLC analyses with conditions as described previously. The analytical availability of freshly spiked soils was already low for lower spiking concentrations (32\% at $1 \mathrm{mg} / \mathrm{kg}, 48 \%$ at $10 \mathrm{mg} / \mathrm{kg}$, and $112 \%$ at $100 \mathrm{mg} / \mathrm{kg}$ ), indicating the tight sorption of tetracycline to soils and mirroring the low recoveries found with the same method [20]. The analytical availability of the tetracycline in microcosm experiment soils amounted to 20 to $36 \%$ on day 1 and 8 to $13 \%$ on day 8 .

\section{RESULTS}

\section{Variation in response}

The first part of this study addresses the variation of community tolerance testing with Biolog plates. One PICT experiment has been repeated in 2003 and 2004: Microcosms of a freshly sampled agricultural soil were amended with slurry and increasing concentrations of tetracycline. After one week, bacterial extracts of the six treatments were inoculated into Biolog Eco-plates that had been amended with additional tetracycline in order to evaluate the overall community tolerance to tetracycline. In this way, differences in the PICT selection step, such as different soil or pig slurry properties, were also included. 


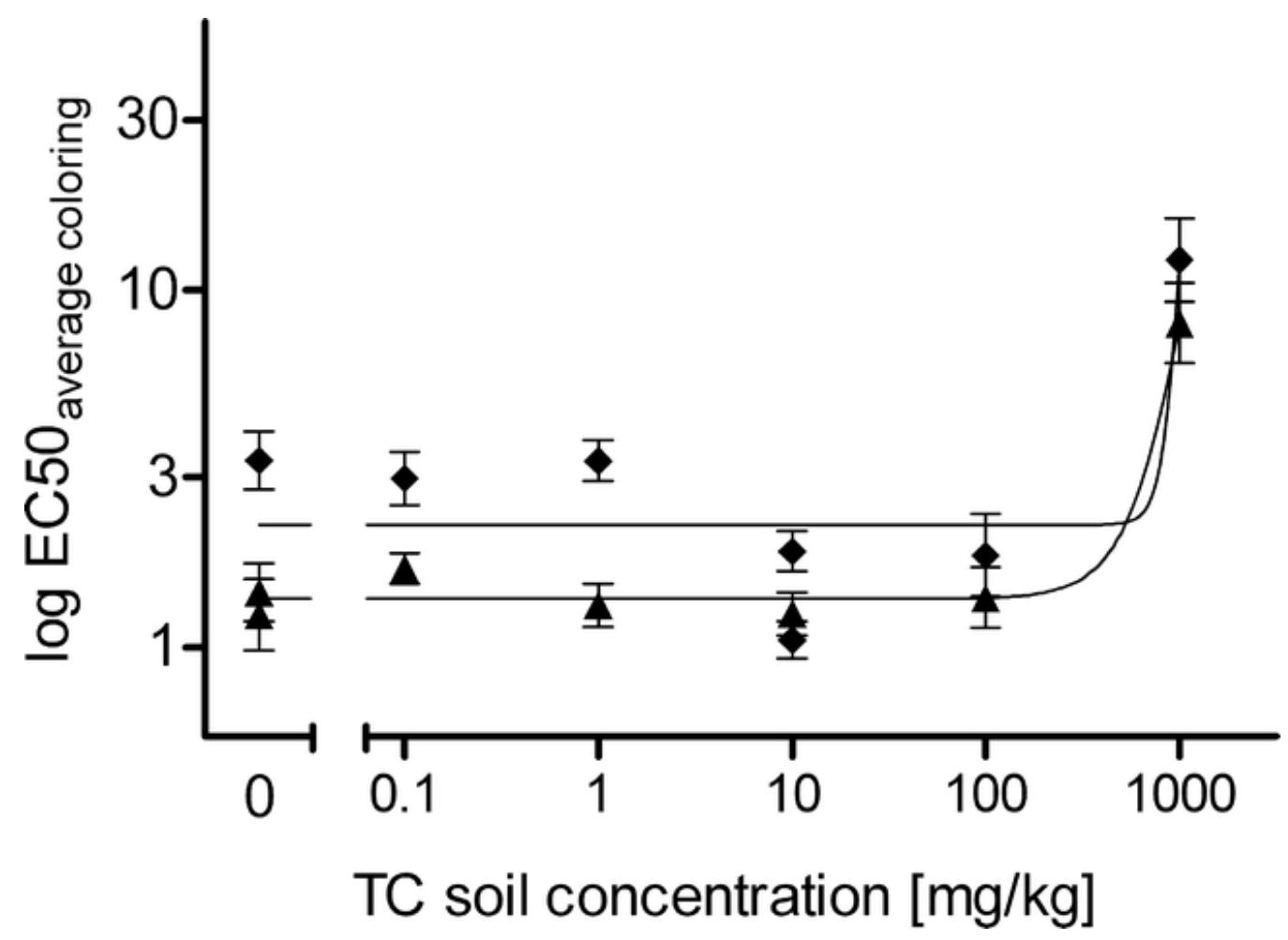

Fig. 1. Pollution-induced tolerance to tetracycline in soil bacteria. The $x$-axis: tetracycline (TC) concentration in soil, $y$-axis: bacterial tolerance, given as the EC50 (the TC concentration needed to decrease the coloring of bacterial extracts in Biolog plates to $50 \%$ of the maximum value). Coloring was determined as the averaged area under the curve of the color development of the responding substrates (ArWCD). Diamonds: experiment performed in 2003; triangles: 2004. The error bars give the standard errors of the mean.

Figure 1 shows the community tolerance in soil samples exposed to increasing concentrations of tetracycline. The community tolerance is given as the concentration of antibiotic causing the utilization of responding substrates (ArWCD) to decrease by $50 \%$ (log EC50). The background tolerance, thus the community sensitivity in the control soils and in the soils exposed to small concentrations of tetracycline, varied from 1 to $3.4 \mathrm{mg} / \mathrm{L}$ in 2003, whereas in 2004, values ranged from 1.2 to $1.7 \mathrm{mg} / \mathrm{L}$.

The increase in community tolerance beyond the baseline tolerance was nearly identical in both years. It was only the highest concentration of $1,000 \mathrm{mg} / \mathrm{kg}$ that caused a significant increase in community tolerance of about a factor of 6 .

Oxytetracycline tolerance was studied in two different experiments, namely, in soils exposed to oxytetracycline ( $\mathrm{H}$. Schmitt, IRAS, Utrecht, The Netherlands, unpublished data) and tylosin (this study). The variance in the oxytetracycline background tolerance of control soils from the two different experiments also yields information on the variation of tolerance determinations in different experiments. The results are shown in Figure 2, which also includes similar data for tylosin. For all measurements, the span between the most extreme values amounted to approximately a factor of 3 (e.g., for tylosin, the range was from 47 to $147 \mathrm{mg} / \mathrm{L})$. 


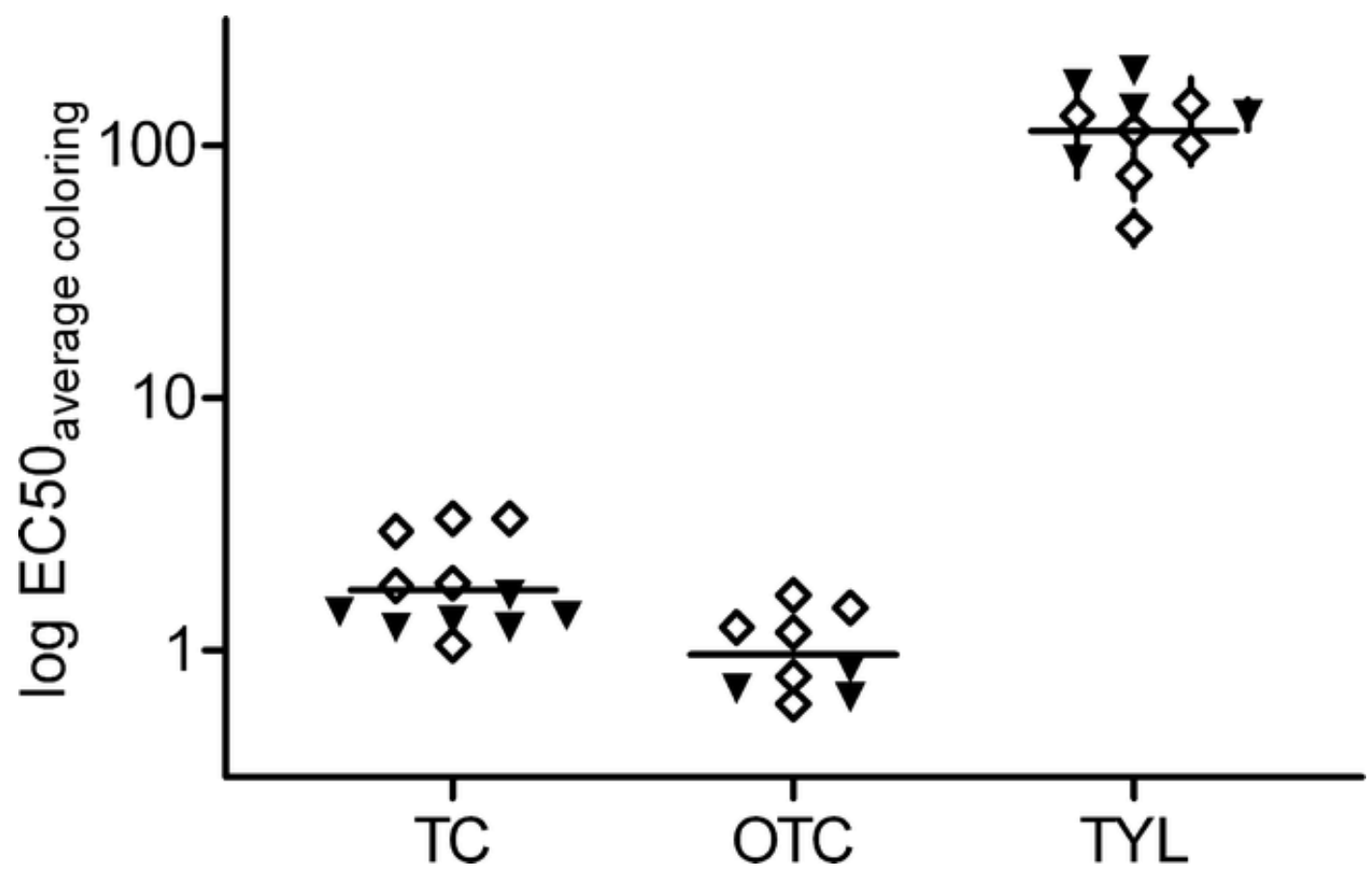

Fig. 2. Reproducibility and variance of tolerance testing. The background tolerance of control soils is compared between different experiments. Tetracycline (TC): tolerance experiments performed in 2003 (open symbols) and 2004 (closed symbols); oxytetracycline (OTC): one tolerance experiment with soil exposed to oxytetracycline (closed symbols) and one cotolerance experiment with soil exposed to tylosin (open symbols); tylosin (TYL): one tolerance (closed symbols) and one cotolerance (open symbols) experiment. The $y$-axis: effective concentration (EC50) resulting in 50\% reduced coloring, with coloring determined as the averaged area under the curve of the color development of the responding substrates (ArWCD). The error bars give the standard error of the mean, if extending beyond the symbols. The horizontal lines give the means for each antibiotic.

\section{Additional effect studies: Selective plating and physiological fingerprints}

Selective plating was used to underpin the findings of the PICT experiment in 2004. The results are shown in Figure 3 for soils exposed to TC for $14 \mathrm{~d}$. Whereas the total counts were nearly identical for all treatments and also constant over time, a greater proportion of bacteria (as CFUs) able to grow on plates amended with $100 \mathrm{mg} / \mathrm{L}$ TC were visible in soils amended with 100 and 1,000 mg/kg TC ( $p$ value for both soil treatments $<0.001$ ). An increase in CFU was also observed in plates amended with $10 \mathrm{mg} / \mathrm{L} \mathrm{TC}$, but only for the highest soil treatment. In addition, it is apparent that the control soil that received water instead of pig slurry and tetracycline showed smaller total counts. While the same trends were seen after $7 \mathrm{~d}$ of soil exposure, the increase in resistant CFU was less than after $14 \mathrm{~d}$, and data were more variable (data not shown). 


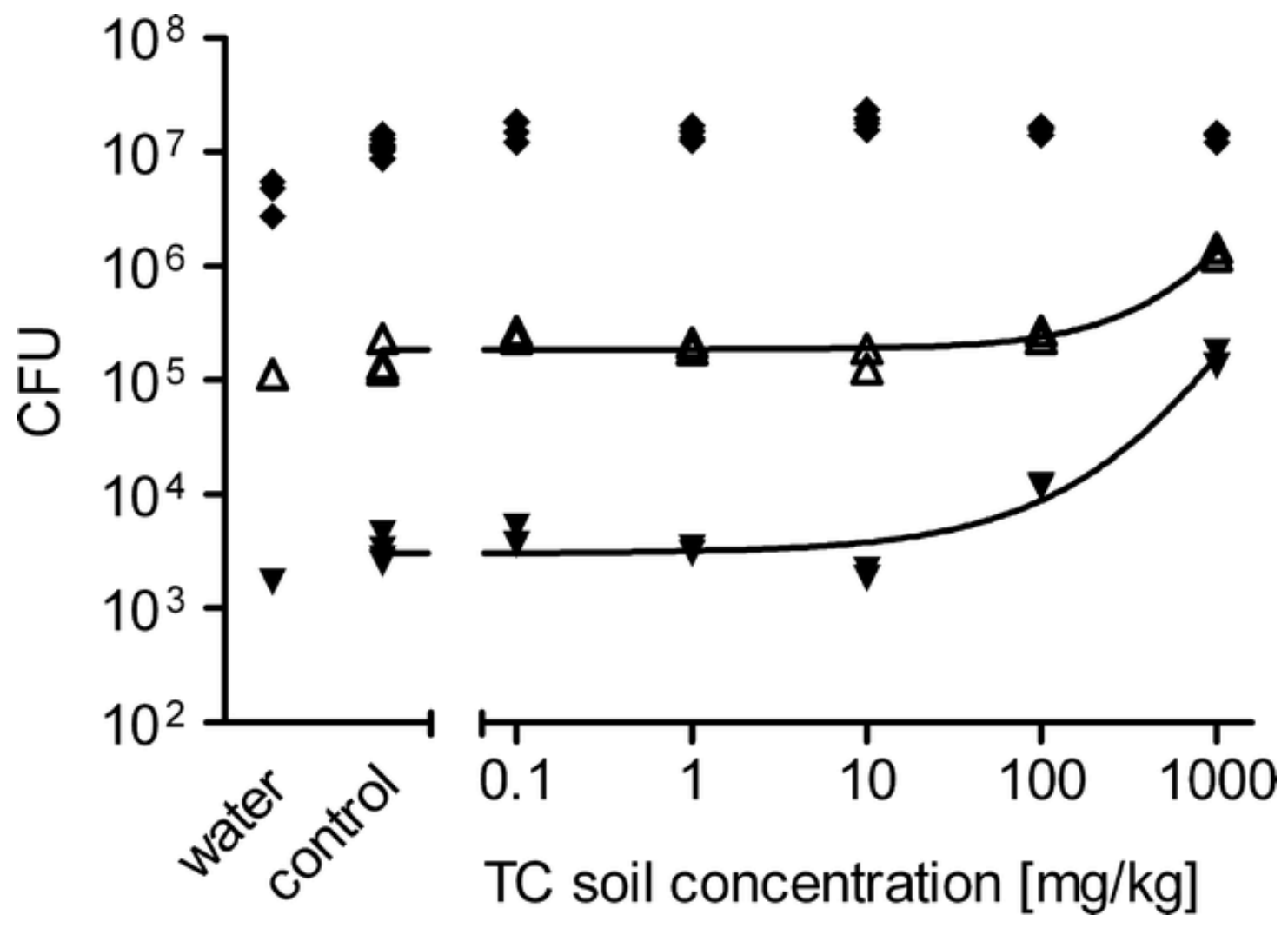

Fig. 3. Bacterial counts on selective agar plates of soils pre-exposed to different concentrations of tetracycline after $14 \mathrm{~d}$. Diamonds: total colony-forming units (CFU) on tetracycline (TC)-unamended plates; open triangles: plates with 10 $\mu \mathrm{g} / \mathrm{ml} \mathrm{TC}$; filled triangles: plates amended with $100 \mu \mathrm{g} / \mathrm{ml} \mathrm{TC}$. Water: soil without manure and TC amendment; control: soil with manure but no TC.

To accomplish the detection of the antibiotic effects with another method addressing the structure of bacterial communities, an analysis of the communitylevel physiological profile (CLPP) has been performed. Figure 4 gives the changes in the pattern of substrate utilization of soil samples spiked with tetracycline in two experiments performed in two consecutive years. As judged by Monte Carlo permutations, the effect of tetracycline is highly significant $(p=0.002)$. Still, the deviation of the soil exposed to the highest TC concentration $(1,000 \mathrm{mg} / \mathrm{kg})$ in 2004 dominates the principal component analysis. No strong trend in the remaining soil samples was observed, only that the highest treatment in 2003 was also slightly shifted to the right on the first axis. On the second axis, the difference between the soil samples of experiments conducted in two consecutive years becomes apparent, as the treatments of both years are separated. 
Environmental Toxicology and Chemistry: No. 25, pp. 1961-1968.

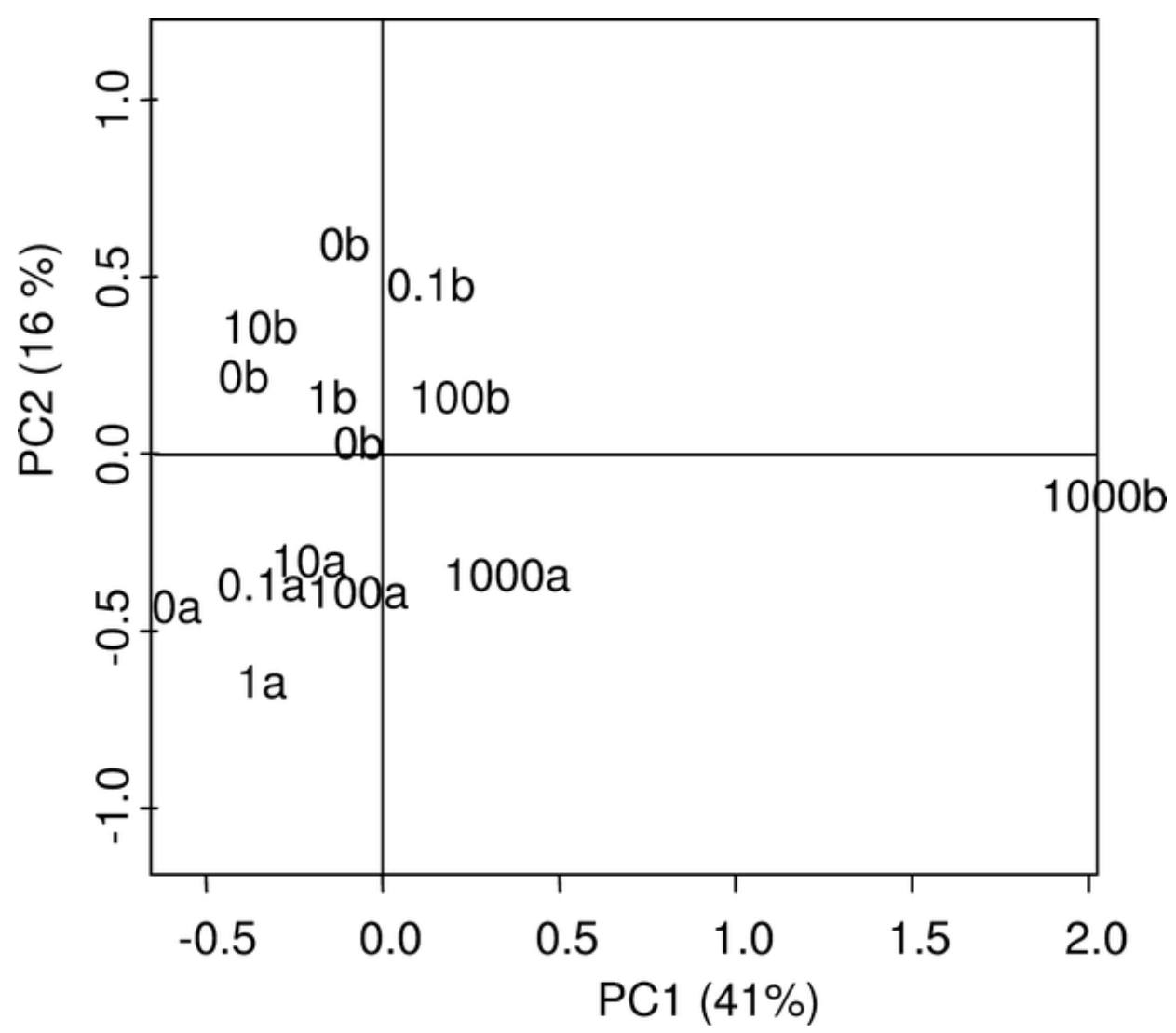

Fig. 4. Community-level physiological fingerprint analysis of soils exposed to tetracycline. Principal component (PC) analysis of the pattern of utilization of 31 substrates by soil microcosms exposed to different concentrations of tetracyclines (concentrations given in $\mathrm{mg} / \mathrm{kg}$ ). Experiments performed in 2003 are marked with a and in 2004 with b. 

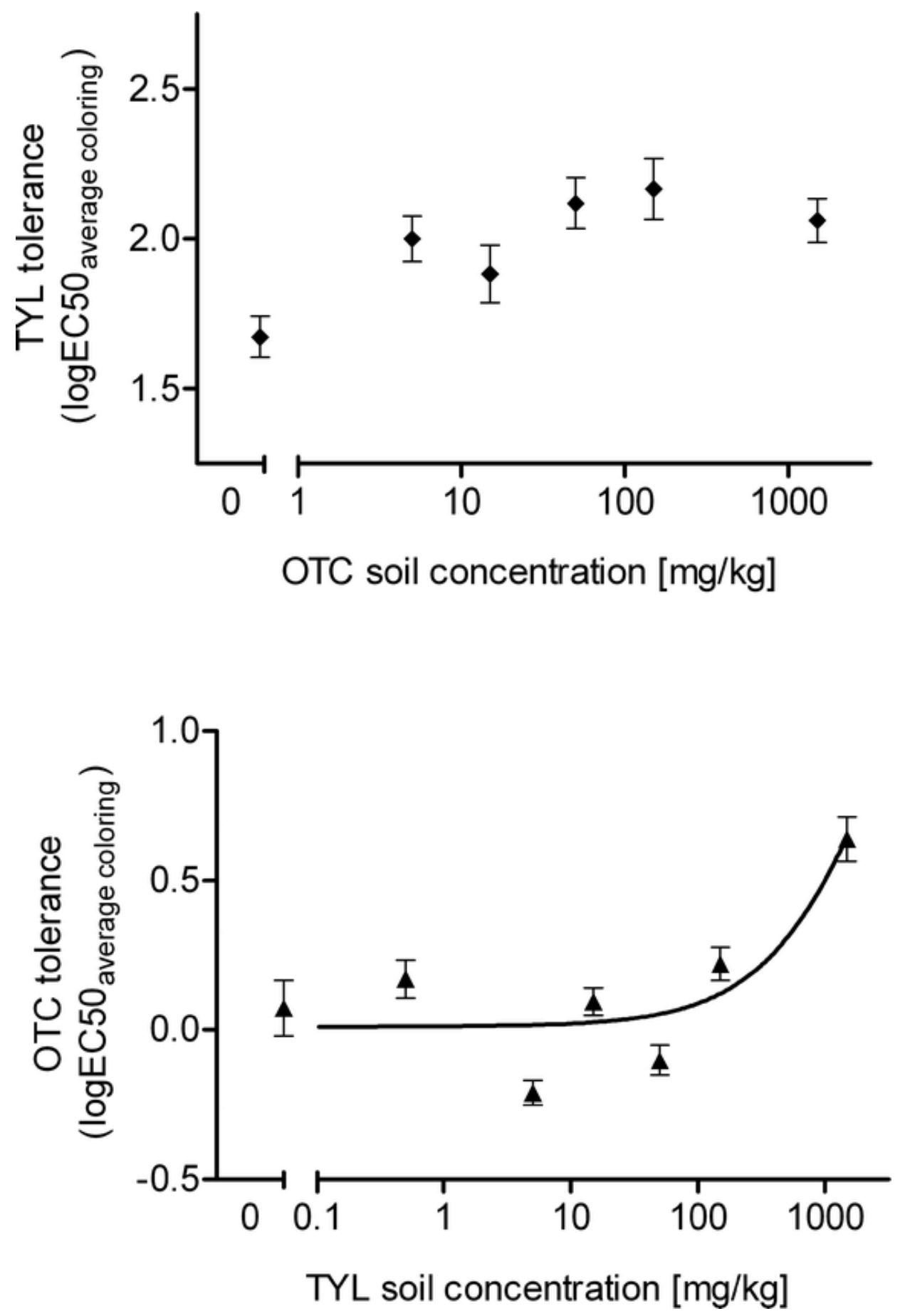

Fig. 5. Cotolerance of soil bacterial communities to a range of antibiotics. Communities stemming from oxytetracycline-exposed soil to tylosin (TYL; left) and from tylosin-exposed soil to oxytetracycline (OTC; right). The $y$-axis: effective concentration (EC50) resulting in 50\% reduced coloring, with coloring determined as the averaged area under the curve of the color development of the responding substrates. The error bars give the standard error of the mean. 


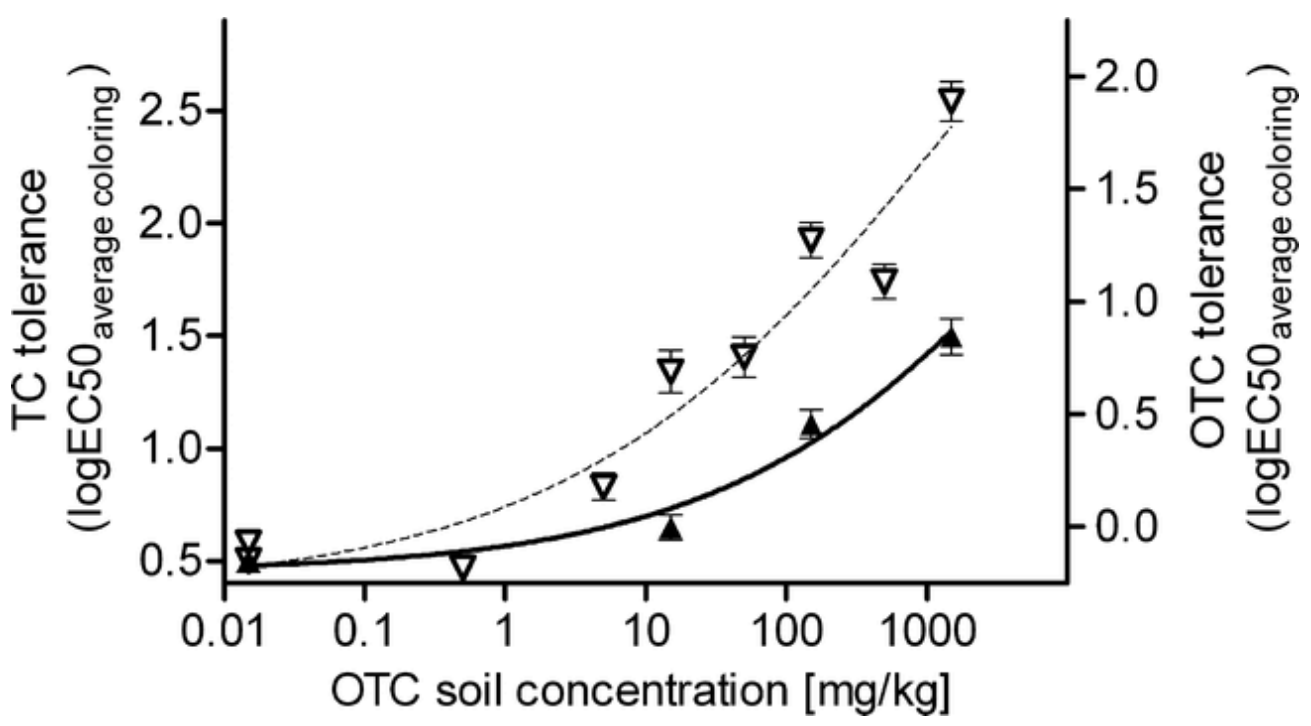

Fig. 6. Cotolerance of soil bacterial communities to a range of antibiotics. Communities stemming from soil exposed to oxytetracycline (OTC) to tetracycline (TC; left axis, closed symbols) and OTC (right axis, open symbols). The $y$-axis: effective concentration (EC50) resulting in $50 \%$ reduced coloring, with coloring determined as the averaged area under the curve of the color development of the responding substrates. The error bars give the standard error of the mean.

\section{Cotolerance}

The second part of this study addresses cotolerance of microbial communities that have become adapted to one antimicrobial agent. Figures 5 and 6 show results from cotolerance experiments with three different combinations of antibiotics. The cotolerances of oxytetracycline and tylosin, antibiotics with a different mode of molecular action, are shown in Figure 5. For oxytetracyclineexposed soils, cotolerance to tylosin was limited to a small increase that is, however, not significant as judged from the confidence intervals. In tylosinexposed soil, the tolerance to oxytetracycline did not change to a great extent. Only in the highest soil treatment was an increase in tolerance by a factor of 4 found. In order to evaluate a case where cotolerance can strongly be expected due to common tolerance mechanisms, the cotolerance of oxytetracyclineexposed soils to tetracycline was evaluated. An increase in the community tolerance to tetracyline started at a soil concentration of $15 \mathrm{mg} / \mathrm{kg}$, as shown in Figure 6. The ultimate community tolerance in a soil exposed to $1,500 \mathrm{mg} / \mathrm{kg}$ oxytetracycline amounted to $31 \mathrm{mg} / \mathrm{L}$ and had therefore increased 10 -fold. Figure 6 also includes the results of the tolerance of oxytetracycline-exposed soils to oxytetracycline ( $\mathrm{H}$. Schmitt, IRAS, Utrecht, The Netherlands, unpublished data). It becomes apparent that the tolerance increase was still significantly higher for oxytetracycline than for tetracycline and that the onset of tolerance increase was at lower concentrations for oxytetracycline than for tetracycline in the same soils. While an increase was observed in oxytetracycline tolerance but not in tetracycline tolerance in the soil exposed to $15 \mathrm{mg} / \mathrm{kg}$ oxytetracycline, a significant increase also in tetracycline tolerance had been found at $150 \mathrm{mg} / \mathrm{kg}$.

\section{Sorption experiment}

In order to be able to compare oxytetracycline and tetracycline with respect to their physicochemical fate in soil and their antimicrobial activity, the sorption coefficient of tetracycline and oxytetracycline has been determined. The sorption 
Environmental Toxicology and Chemistry: No. 25, pp. 1961-1968.

coefficient, $K_{\mathrm{d}}$, of tetracycline determined in this study was $1,714 \pm 418 \mathrm{~L} / \mathrm{kg}$, which is slightly lower than for oxytetracycline $(2,556 \mathrm{~L} / \mathrm{kg} ; \mathrm{H}$. Schmitt, IRAS, Utrecht, The Netherlands, unpublished data). The weaker sorption of tetracycline is thus expected to lead to an increased bioavailability of dissolved tetracycline in the soil pore water.

\section{DISCUSSION}

\section{Effects of tetracycline on soil microbial communities}

Figure 1 shows that an increase in community tolerance due to soil amendment with tetracycline has been consistently observed in two independent experiments: Concentrations of $1,000 \mathrm{mg} / \mathrm{kg}$ tetracycline led to a rise in community tolerance from about 1.5 to $10 \mathrm{mg} / \mathrm{L}$. Effects might also occur at lower concentrations, though: After $14 \mathrm{~d}$, an increase in tetracycline-tolerant CFUs was also seen for the $100-\mathrm{mg} / \mathrm{kg}$ soil treatment. The overall community tolerance thus kept increasing after one week of soil exposure with tetracycline and pig slurry.

The effects of tetracycline seen in our study are in accordance with another soil microcosm study [21] where slight effects of tetracycline in pig slurry-amended soil microcosms at concentrations of about $500 \mathrm{mg} / \mathrm{kg}$ were observed. In their investigation, Hund-Rinke et al. found a reduction in substrate-induced respiration and a reduced number of phospholipid fatty acids after an exposure of 8 and 16 weeks. The community tolerance increase is thus likely to be paired with a reduction in the microbial diversity due to loss of sensitive species or preferential growth of more tolerant bacteria.

\section{Comparison of tetracycline and oxytetracycline effects}

Tetracycline and oxytetracycline share the same bacteriostatic mode of action of inhibiting bacterial protein synthesis through interaction with the ribosome [22]. Thus, their ecotoxicity could be expected to be comparable, given that their structures and therewith their physicochemical behavior are also much alike. In contrast, we found that the effects of tetracycline differ greatly from oxytetracycline. In the case of oxytetracycline, we detected a steady tolerance increase that started in the low $\mathrm{mg} / \mathrm{kg}$ range $(\mathrm{H}$. Schmitt, IRAS, Utrecht, The Netherlands, unpublished data), whereas an increase in tolerance occurred at much higher concentrations for tetracycline.

In order to understand this diverging behavior, we studied the strength of soil sorption, which is an important factor for the bioavailable pore-water fraction. Tetracycline $\left(K_{\mathrm{d}} 1,714 \mathrm{~L} / \mathrm{kg}\right)$ was shown to sorb less strongly than oxytetracycline with a $K_{\mathrm{d}}$ of $2,556 \mathrm{~L} / \mathrm{kg}$ (Fig. 6 ; data taken from $\mathrm{H}$. Schmitt, IRAS, Utrecht, The Netherlands, unpublished data) and is thus even more available than oxytetracycline. Differences in sorption are thus not the reason for the diverging strength of the microbial effects of both compounds.

The inherent antimicrobial activity of the two substances might also explain the observed differences between oxytetracycline and tetracycline. The EC50 values for control, unexposed soil communities determined in Biolog plates amount to about $1(0.72-1.25) \mathrm{mg} / \mathrm{L}$ for oxytetracycline and to approximately 1.7 (1.342.3) $\mathrm{mg} / \mathrm{L}$ for tetracycline. Thus, oxytetracycline is slightly more effective. Still, the effects of a slightly lower equilibrium sorption coefficient and a slightly lower inherent toxicity of tetracycline as opposed to oxytetracycline should compensate. 
Apart from diverging intrinsic properties of the substances, the different results found in both experiments can also be due to experimental parameters like the nutrient input into the system. Indeed, differences were observed between both years: In 2003 and 2004, the input into the system was about 0.45 and $1.1 \mathrm{~g}$ dry matter/kg dry weight soil, respectively, and for the oxytetracycline experiment, this was about $2.9 \mathrm{~g}$ dry matter/kg dry weight soil. The reason for this difference was that the pig slurry addition had been adjusted to the nitrogen content of the slurry, according to European Union guidelines limiting the nitrogen input to 170 $\mathrm{kg} \mathrm{N} /$ ha soil. However, the nitrogen content in slurry was variable, resulting in a different carbon input. A more intensive growth of bacteria after the slurry amendment could lead to a stronger induced tolerance, as the bacteriostatic tetracyclines show the greatest effect and therewith the strongest selection pressure during bacterial growth phases [16,23-26]. The fact that the tetracycline tolerance continued to increase after one week, which was not the case for the oxytetracycline tolerance, adds to the idea that the tetracyclineexposed communities had not yet reached the maximum tolerance gain because of a lower nutrient availability.

\section{Variation in response}

Results of two dose-response studies with tetracycline in two consecutive years allowed for an estimation of the intralaboratory variation. The tolerances for unstressed communities were only slightly higher in 2003 (2.2 vs $1.3 \mathrm{mg} / \mathrm{L})$. In contrast to the difference of factor 1.7 in the background tolerance, the increase in tolerance detected in both years has been nearly identical (factor 5.5 in 2003 and factor 6.2 in 2004).

The intralaboratory variance observed between the tolerance and cotolerance experiments with one substance was in the same order as in the tetracycline experiment (Fig. 2). The standard deviations of the pooled EC50 values are in the range of $0.15 \mathrm{log}$ units for all experiments (data not shown). The coefficient of variation, a measure used for interexperiment comparison of variation, amounts to $44.6,32.9$, and $37.5 \%$ for tetracycline, tylosin, and oxytetracycline, respectively ( $n=12,10$, and 9). Other investigations based on Biolog plates come to a comparable coefficient of variation for different soil nutrient amendments (42\% in a laboratory experiment with sulfachloropyridazine [27] or $16-55 \%$ at different field sites that were not contaminated with metals [12]). Overall, the variation is in the range as observed for intralaboratory variation in other complex ecotoxicological test systems $[28,29]$. Although a coefficient of variation of smaller than $30 \%$ is generally aimed at, this criterion is frequently exceeded in test systems with difficult environmental media such as soil, with difficult polar and degrading test substances, and with nonstandardized communities in place of single standardized test species.

Interestingly, the variation seen in the PICT determinations is still smaller than seen in the CLPP experiment. In one experiment, the fingerprints agree with the PICT findings (clear effect of the highest treatment on the metabolic fingerprint), whereas in the other experiment, the effect of the antibiotic treatment was much smaller, probably because other parameters also affected the physiological fingerprints. This is in line with previous experiments where differences in the soil nutrient level affected the physiological fingerprint, but not the community tolerance [27]. Overall, the results corroborate with the idea that the PICT approach is especially sensitive for the detection of toxicant impacts. In addition, the effects observed in the PICT experiments have been underpinned by the results of selective plating, where again the PICT experiment showed a more clear effect than the colony counts after $7 \mathrm{~d}$. 
Environmental Toxicology and Chemistry: No. 25, pp. 1961-1968.

In conclusion, although PICT measurements in soil microcosms showed some variation, effects could still well be reproduced in independent experiments. Thus, Biolog plates can be applied for PICT determinations of antibiotics.

\section{Cotolerance}

The second part of this study addresses cotolerance of microbial communities to different antibiotics. For antibiotics with an identical mode of action and identical resistance mechanisms, cotolerance was observed as expected: Oxytetracycline-exposed soils also showed an increased tolerance to tetracycline. Still, the tetracycline cotolerance was weaker than the tolerance to oxytetracycline: A doubling in community tolerance occurred at $1.3 \mathrm{mg} / \mathrm{kg}$ oxytetracycline but at $19 \mathrm{mg} / \mathrm{kg}$ for tetracycline, respectively (Fig. 6). Further, the total tolerance gain was bigger for oxytetracycline (increase in EC50 by a factor of 130) than for tetracycline (factor of 11).

In a PICT investigation with periphyton communities and a range of herbicidal compounds, it appeared that the tolerance gain in diuron-exposed communities varied from a factor 6.5 to 11 for photosystem II inhibitors with a similar mode of action. Cotolerance was sometimes even higher than the tolerance gain for the original compound, diuron [30]. It has thus been concluded before that cotolerance seems to be a graded response rather than a presence-absence phenomenon [2]. The difference in the level of tolerance to oxytetracycline and cotolerance to tetracycline observed in our study supports this notion.

Interestingly, the tetracycline tolerance increase in the oxytetracyclineamended soil (Fig. 6) was even greater than in the tetracycline-amended soil (Fig. 1): Tolerance increased by a factor of 10 . Further, the soil amended with $150 \mathrm{mg} / \mathrm{kg}$ oxytetracycline already showed a clear tolerance increase, whereas no effect had been seen at $100 \mathrm{mg} / \mathrm{kg}$ tetracycline amendment. Again, that points to the possibility that the conditions in the oxytetracycline experiment were in favor of a stronger tolerance development, for example, because of a stronger bacterial growth in that system. Still, a stronger effect of an alternative selection pressure has also been observed by Díaz-Raviña et al. [5] for nickel tolerance in copperexposed soils.

Our experiments do not resolve whether the observed cotolerance was due to an increase in tetracycline-resistant bacteria. Still, the observed cotolerance between different tetracyclines supports the current policy of avoiding the use of compounds of the same antibiotic class in different application areas, such as growth promotion and human medication.

For antibiotics with a different mode of action, cotolerance was limited. This finding suggests that the reservoir of soil bacteria with multiple antibiotic resistances is not big enough to easily render the whole community cotolerant when exposed to one antibiotic. It has previously been speculated that cotolerance could be more prominent among bacteria than among higher species because of the ease of transfer of genetic elements and to the colocation of resistance genes on mobile genetic elements such as plasmids [1]. Unfortunately, little data exist on multiple resistances of soil microorganisms to both tetracyclines and macrolides with which to compare our results. In isolates of farm animals, multiple resistances to tetracyclines, streptomycin, and sulfonamides are most frequently reported [31]. The level of resistance to macrolides in strains isolated from farm animals or slurry samples is sometimes in the same range as tetracycline resistance [32] and sometimes lower [33]. Further, macrolide and tetracycline resistance genes sometimes coreside on 
conjugative transposons found in Bacteroides species [34,35]. Compared with bacterial isolates from farm animals, the presence of resistant bacterial strains in environmental compartments not impacted by antibiotics is controversial: Whereas some investigators report a lower frequency of resistance in remote areas $[36,37]$, some studies find highly resistant bacteria also in situations without antibiotic pressure [38]. Thus, it is difficult to say whether the limited cotolerance observed in our study is due to a limited occurrence of easily transferable genetic elements with multiple antibiotic resistances or due to other reasons, such as a low transfer frequency or a predominance of other tolerance mechanisms.

In our study, cotolerance between different compound classes has been observed in one soil microcosm: The highest concentration of tylosin caused an increase in the oxytetracycline tolerance as well. As this effect occurs only with the highest concentration of tylosin, this cotolerance might be caused by selective depletion of the community at that concentration and the intrinsic tolerance of the remaining soil bacteria. Tylosin is indeed known to have selective activity: It belongs to the narrow-spectrum macrolides that affect mostly Gram-positive cocci and bacilli as well as Gram-negative cocci [39]. Oxytetracycline, in contrast, is a broad-spectrum agent [22].

Our results confirm other studies that showed a limited cotolerance for structurally unrelated compounds, for example, for different uncouplers and photosynthetic inhibitors $[30,40]$. On the other hand, cotolerance has been frequently observed for metals, for example, between copper, cadmium, and zinc, as observed in field and microcosm experiments $[4-6,41]$. Although metal cotolerance has often been described, the reasons for this phenomenon are not generally agreed on. The same holds true for the cotolerance observed between two structurally unrelated compounds, diuron and tributyltin, in periphyton communities [42].

Overall, the small cotolerance between different antibiotic agents was small. However, this does not relieve the notion that cotolerance might be a limiting factor for the application of PICT to investigate the relevance of a certain toxicant in a given system. Still, cotolerance should not be assumed as a general rule but rather be evaluated for toxicants suspected to act as selecting stressors on a case-by-case basis.

In summary, we observed that the variation linked to the results of PICT determinations in controlled microcosms is comparable to normal variation in ecotoxicological test systems of equivalent complexity, which points to the suitability of the use of Biolog plates for PICT determinations in soil microcosms. Further, in our experiments, PICT was specific for chemical substances with comparable tolerance mechanisms, but little cotolerance was observed between different groups of antibiotic compounds.

\section{Acknowledgments}

We thank K. van Leeuwen, A. Breure, and E. Smit for critically commenting on the manuscript and A.-M. Jacobsen and P. Blackwell for providing the methods for tetracycline analysis.

\section{References}

1. Blanck H, Wängberg S- $\AA$, Molander S. 1988. Pollution-induced community tolerance-A new ecotoxicological tool. In Cairns J, Pratt JR, eds, Functional Testing of Aquatic Biota for Estimating Hazards of Chemicals. STP 988. American Society for Testing and Materials, Philadelphia, PA, pp 219230. 
2. Blanck H. 2002. A critical review of procedures and approaches used for assessing pollution-induced community tolerance (PICT) in biotic communities. Human and Ecological Risk Assessment. 8:10031034

3. Boivin M-E, Breure AM, Posthuma L, Rutgers M. 2002. Determination of field effects of contaminants-Significance of pollution-induced community tolerance. Human and Ecological Risk Assessment. 8:1035-1055.

4. Bååth E, Díaz-Raviña M, Frostegård $\AA$, Campbell C. 1998. Effect of metal-rich sludge amendments on the soil microbial community. Appl Environ Microbiol. 64:238-245.

5. Díaz-Raviña M, Bååth E, Frostegård A. 1994. Multiple heavy metal tolerance of soil bacterial communities and its measurement by a thymidine incorporation technique. Appl Environ Microbiol. 60:2238-2247.

6. Soldo D, Behra R. 2000. Long-term effects of copper on the structure of freshwater periphyton communities and their tolerance to copper, zinc, nickel, and silver. Aquat Toxicol. 47:181-189.

7. Tennstedt T, Szczepanowski R, Braun S, Pühler A, Schlüter A. 2003. Occurrence of integronassociated resistance gene cassettes located on antibiotic resistance plasmids isolated from a wastewater treatment plant. FEMS Microbiol Ecol. 45:239-252.

8. Fernandez-Moreno MA, Carbo L, Cuesta T, Vallin C, Malpartida F. 1998. A silent ABC transporter isolated from Streptomyces rochei F20 induces multidrug resistance. J Bacteriol. 180:4017-4023.

9. Schmitt H, van Beelen P, Tolls J, van Leeuwen CJ. 2004. Pollution-induced community tolerance of soil microbial communities caused by the antibiotic sulfachloropyridazine. Environ Sci Technol. 38:1148-1153.

10. American Academy of Microbiology. 2002. The role of antibiotics in agriculture. Washington, DC.

11. Davis MR, Zhao FJ, McGrath SP. 2004. Pollution-induced community tolerance of soil microbes in response to a zinc gradient. Environ Toxicol Chem. 23:2665-2672.

12. van Beelen P, Wouterse M, Rutgers M, Posthuma L. 2004. Location-specific ecotoxicological risk assessment of metal-polluted soils. Environ Toxicol Chem. 23:2769-2779.

13. Siciliano SD, Gong P, Sunahara GI, Greer CW. 2000. Assessment of 2,4,6-trinitrotoluene toxicity in field soils by pollution-induced community tolerance, denaturing gradient gel electrophoresis, and seed germination assay. Environ Toxicol Chem. 19:2154-2160.

14. Rutgers M, van't Verlaat IM, Wind B, Posthuma L, Breure AM. 1998. Rapid method for assessing pollution-induced community tolerance in contaminated soil. Environ Toxicol Chem. 17:2210-2213.

15. Garbeva $P$, van Veen JA, van Elsas JD. 2003. Predominant Bacillus spp. in agricultural soil under different management regimes detected via PCR-DGGE. Microb Ecol. 45:302-316.

16. Schmitt H, Haapakangas $H$, van Beelen P. 2005. Effects of antibiotics on soil microorganisms: Time and nutrients influence pollution-induced community tolerance. Soil Biol Biochem. 37:18821892.

17. Rutgers M, Breure AM, Insam H. 2006. 8.4. Substrate utilisation in Biolog plates for analysis of CLPP. In Bloem J, Hopkins DW, Benedetti A, eds, Microbiological Methods for Assessing Soil Quality. CAB International, Wallingford, UK, pp 212-227.

18. van Beelen P, Fleuren-Kamilä AK, Huys MPA. 1991. The toxic effects of pollutants on the mineralization of acetate in subsoil microcosms. Environ Toxicol Chem. 10:775-789.

19. Organization for Economic Cooperation and Development. 2000. Adsorption-desorption using a batch equilibrium method. Guideline 106. Paris, France.

20. Blackwell PA, Holten Lützhøft H-C, Ma H-P, Halling-Sørensen B, Boxall ABA, Kay P. 2004. Ultrasonic extraction of veterinary antibiotics from soils and pig slurry with SPE clean-up and LC- UV and fluorescence detection. Talanta. 64:1058-1064.

21. Hund-Rinke K, Simon M, Lukow T. 2004. Effects of tetracycline on the soil microflora: Function, diversity, resistance. Journal of Soils and Sediments. 4:11-16.

22. Chopra I, Roberts M. 2001. Tetracycline antibiotics: Mode of action, applications, molecular biology, and epidemiology of bacterial resistance. Microbiol Mol Biol Rev. 65:232-260. 
Environmental Toxicology and Chemistry: No. 25, pp. 1961-1968.

23. Backhaus T, Froehner K, Altenburger R, Grimme LH. 1997. Toxicity testing with Vibrio fischeri: A comparison between the long term ( $24 \mathrm{~h}$ ) and the short term (30 min) assay.

Chemosphere. 12:2925-2938.

24. Froehner K, Backhaus T, Grimme LH. 2000. Bioassays with Vibrio fischeri for the assessment of delayed toxicity. Chemosphere. 40:821-828.

25. Kümmerer K, Alexy R, Hüttig J, Schöll A. 2004. Standardized tests fail to assess the effects of antibiotics on environmental bacteria. Water Res. 38:2111-2116.

26. Thiele S, Beck I-C. 2001. Wirkungen pharmazeutischer Antibiotika auf die BodenmikrofloraBestimmung mittels ausgewählter bodenbiologischer Testverfahren. Mitteilungen der Deutschen Bodenkundlichen Gesellschaft. 96:383-384.

27. Schmitt $H$, Haapakangas $H$, van Beelen P. 2005. Effects of antibiotics on soil microorganisms: Time and nutrients influence pollution-induced community tolerance. Soil Biol Biochem. 37:18821892.

28. Moore DRJ, Warren-Hicks W, Parkhurst BR, Teed RS, Baird RB, Berger R, Denton DL, Pletl JJ. 2000. Intra- and intertreatment variability in reference toxicant tests: Implications for whole effluent toxicity testing programs. Environ Toxicol Chem. 19:105-112.

29. Broos K, Mertens J, Smolders E. 2005. Toxicity of heavy metals in soil assessed with various soil microbial and plant growth assays: A comparative study. Environ Toxicol Chem. 24:634-640.

30. Molander S. 1991. Detection, validity and specificity of pollution-induced community tolerance (PICT). PhD thesis, University of Göteborg, Göteborg, Sweden.

31. Guerra B, Junker E, Schroeter E, Malorny B, Lehmann S, Helmuth R. 2003. Phenotypic and genotypic characterization of antimicrobial resistance in German Escherichia coli isolates from cattle, swine and poultry. J Antimicrob Chemother. 52:489-492.

32. Cotta MA, Whitehead TR, Zeltwanger RL. 2003. Isolation, characterization and comparison of bacteria from swine faeces and manure storage pits. Environ Microbiol. 5:737-745.

33. Hayes JR, English LL, Carter PJ, Proescholdt T, Lee KY, Wagner DD, White DG. 2003. Prevalence and antimicrobial resistance of Enterococcus species isolated from retail meats. Appl Environ Microbiol. 69:7153-7160.

34. Courvalin P, Carlier C. 1986. Transposable multiple antibiotic resistance in Streptococcus pneumoniae. Mol Gen Genet. 205:291-297.

35. Caillaud F, Carlier C, Courvalin P. 1987. Physical analysis of the conjugative shuttle transposon Tn1545. Plasmid. 17:58-60.

36. Esiobu N, Armenta L, Ike J. 2002. Antibiotic resistance in soil and water environments. Int J Environ Health Res. 12:133-144.

37. Heuer $\mathrm{H}$, Krögerrecklenfort E, Wellington EMH, Egan S, van Elsas JD, van Overbeek L, Collard J-M, Guillaume G, Karagouni AD, Nikolakopoulou TL, Smalla K. 2002. Gentamicin resistance genes in environmental bacteria: Prevalence and transfer. FEMS Microbiol Ecol. 42:289-302.

38. Stanton TB, Humphrey SB. 2003. Isolation of tetracycline-resistant Megasphaera elsdenii strains with novel mosaic gene combinations of tet(O) and tet(W) from swine. Appl Environ Microbiol. 69:3874-3882.

39. Nakajima Y. 1999. Mechanisms of bacterial resistance to macrolide antibiotics. J Infect Chemother. 5:61-74.

40. Blanck H, Wängberg S- $\AA$. 1991. Pattern of cotolerance in marine periphyton communities established under arsenate stress. Aquat Toxicol. 21:1-14.

41. Gustavson K, Wångberg S- $\AA$. 1995. Tolerance induction and succession in microalgae communities exposed to coper and atrazine. Aquat Toxicol. 32:283-302.

42. Molander S, Dahl B, Blanck H, Jonsson J, Sjöström M. 1992. Combined effects of tri-n-butyl tin (TBT) and diuron on marine periphyton communities detected as pollution-induced community tolerance. Arch Environ Contam Toxicol. 22:419-427. 